Çukurova Üniversitesi Mühendislik Mimarlık Fakültesi Dergisi, 33(4), ss. 213-224, Aralık 2018

Çukurova University Journal of the Faculty of Engineering and Architecture, 33(4), pp. 213-224, December 2018

\title{
Tam Ölçekli Bir İleri Biyolojik Evsel Atıksu Arıtma Tesisinin Matematiksel Modellemesi
}

\author{
Hazal GÜLHAN*1, Mustafa Evren ERŞAHIN ${ }^{1}$, Recep Kaan DERELI' ${ }^{1}$, \\ Hale ÖZGÜN ${ }^{1}$, Faik Dinçer ERKAN²${ }^{2}$, Özgür ÖZDEMİR ${ }^{2}$, İzzet ÖZTÜRK ${ }^{1}$ \\ ${ }^{1}$ İstanbul Teknik Üniversitesi, İnşaat Fakültesi, Çevre Mühendisliği Bölümü, Ayazağa Kampüsü, \\ Istanbul \\ ${ }^{2}$ Malatya Su ve Kanalizasyon İdaresi, Malatya
}

Geliş tarihi: 12.02.2018 Kabul tarihi: 25.12 .2018

$\ddot{\mathbf{O z}}$

Atıksu arıtma prosesleri üzerine yürütülen araştırmalarda; atıksu arıtma tesisi tasarımı, farklı çevresel ve işletme şartları altında sistem performansının tahmini, proses iyileştirmesi ve kontrolü gibi birçok farklı amaç için modelleme yaklaşımı kullanılabilmektedir. Bu çalışmanın amacı, nütrient giderimi yapan tam ölçekli bir evsel atıksu arıtma tesisinin matematiksel olarak modellenmesidir. Bu kapsamda, International Water Association (IWA) Aktif Çamur Modeli No 2d (ASM2d) ve General Purpose Simulator (GPS-X) Sürüm 6.5 simülasyon yazılımı kullanılmıştır. İncelenen atıksu arıtma tesisine ait işletme şartlarının ve atıksu karakterizasyonunun arıtma performansına etkilerinin belirlenmesi amacıyla farklı senaryolar incelenmiştir. Modelleme çalışması sonucunda giriş azot yükü ve içsel geri devir (IR) oranının çıkış toplam azot (TN) konsantrasyonu üzerindeki etkileri karşılaştırılmış, mevcut durumdaki azot yükünü gidermek üzere 4,4 IR oranı ile çalıştırılan tesisin, 2,5 IR oranı ile çalıştırıldığında da $10 \mathrm{mg} / \mathrm{L}$ 'nin altında TN deşarj konsantrasyonunu sağlayabileceği görülmüştür. Bununla birlikte, atıksu azot yükü ile denitrifikasyon prosesi hacminin, deşarj TN konsantrasyonuna etkisi karşılaştırılmış ve incelenen atıksu arıtma tesisinde enerji tasarrufu sağlayacak işletme koşulları tespit edilmiştir.

Anahtar Kelimeler: Atıksu arıtma tesisi, Denitrifikasyon, Evsel atıksu, Matematiksel modelleme, Nitrifikasyon

\section{Mathematical Modelling of a Full Scale Advanced Biological Municipal Wastewater Treatment Plant}

\begin{abstract}
Modelling can be applied for several purposes such as wastewater treatment plant design, estimation of system performance under different environmental and operational conditions, process enhancement and control in the studies related with wastewater treatment processes. The objective of this study is to apply a mathematical model to a full-scale municipal wastewater treatment plant. Within this concept, by using International Water Association (IWA) Activated Carbon Model No 2d (ASM2d) and General Purpose Simulator (GPS-X) version 6.5 simulation software, various scenarios were investigated in order to
\end{abstract}

\footnotetext{
${ }^{1}$ Sorumlu yazar (Corresponding author): Hazal GÜLHAN, gulhan@itu.edu.tr
} 
determine the effect of operational conditions and wastewater characterization on treatment performance. As a result of modeling studies, the effect of influent nitrogen load and internal recycle (IR) ratio on effluent total nitrogen (TN) concentration were comparatively evaluated and it was concluded that effluent TN concentration below $10 \mathrm{mg} / \mathrm{L}$ could still be achieved if IR ratio of the system decreased from 4 to 2.5 . In addition to that, the effect of wastewater nitrogen load and denitrification process volume on effluent TN concentration were comparatively evaluated and operational conditions, that provided energy savings, were determined in the investigated wastewater treatment plant.

Keywords: Wastewater treatment plant, Denitrification, Municipal wastewater, Mathematical modeling, Nitrification

\section{GIRISs}

Evsel atıksu kaynaklı kirlilik; doğrudan insan sağlığını etkilemesi ve alıcı ortam ile içme suyu kaynakları için büyük risk oluşturması sebebiyle oldukça önemlidir [1]. Birçok ülkede evsel atıksular, düşük kuvvetli ve hizmet edilen nüfusa bağlı olarak yüksek debide oluşmaktadır [2]. Mevcut durumda, evsel atıksu aritma tesislerinde enerji kullanımı dünyadaki elektrik enerjisi kullanımının yaklaşık \%3'üne denk gelmektedir [3]. Bu açıdan değerlendirildiğinde; son yıllarda evsel atıksu arıtımında yüksek enerji tüketimi olan konvansiyonel sistemler yerine enerji açısından verimli ve kaynak geri kazanımına elverişli sistemler tercih edilmeye başlanmıştır [1].

Biyolojik atıksu arıtma tesisleri fiziksel, kimyasal ve biyolojik proseslerin bir arada uyumlu bir şekilde çalıştığ1 mühendislik sistemleridir. Atıksu arıtımında oldukça yaygın kullanılan biyolojik prosesler birçok mikroorganizma grubunun faaliyetleri sonucu gerçekleşmekte olup, oldukça karmaşık süreçler içermektedir. Çevre bilimleri ve mühendisliğinde matematiksel modelleme bu süreçlerin daha iyi anlaşılmasını sağlayan önemli bir araçtır. Atıksu arıtma tesislerinde yer alan fiziksel, kimyasal ve biyolojik prosesler için bugüne kadar birçok matematiksel model geliştirilmiştir. Atıksu arıtma prosesleri üzerine yürütülen araştırmalarda aktif çamur modelleri yaygın olarak kullanılmakta olup, bu modeller arasında en çok kullanılanları International Water Association (IWA) çalışma grupları tarafından geliştirilen Aktif Çamur Modeli (ASM) No. 1, 2d ve 3'tür [4]. Bu modeller günümüzde standart modeller olarak kabul edilmekte olup, General Purpose Simulator (GPS-X), Aquasim, Biowin, West, Matlab/
Simulink gibi birçok ticari veya açık kaynak simülasyon yazılımında uygulanmış durumdadır. Aktif çamur modelleri atıksu arıtma tesisi tasarımı, farklı çevresel ve işletme şartları altında sistem performansının tahmini, proses iyileştirmesi ve kontrolü gibi birçok farklı amaç için kullanılabilmektedir. $\mathrm{Bu}$ şekilde bilimsel araştırmalar ve laboratuvar çalışmalarında elde edilen bilginin atıksu arıtma sistemlerine transferi kolaylaşmakta, laboratuvar çalışmalarında zaman ve maliyet optimizasyonu yapılabilmekte ve aritma tesislerinin farklı dinamik koşullar altındaki performansı sistem riske atılmadan test edilebilmektedir.

Nütrient giderimi yapan atıksu arıtma tesisleri için nitrifikasyon prosesinin modellenmesi ile ilgili gerçekleştirilen ilk çalışmalardan biri 1964 yılında yapılmıştır. Yapılan bu çalışma ile kütle dengesi ve kinetik ilişkiler gibi kavramlar literatüre kazandırılmıştır [5]. Dold ve arkadaşları [6] aktif çamur proseslerinde organik maddenin parçalanması, nitrifikasyon, denitrifikasyon ve oksijen tüketimi süreçlerinin dinamik davranışlarının modellenmesi konusunda çalışmalar gerçekleştirmiştir. Substratın kolay ayrışabilir ve yavaş ayrışabilir olarak iki temel bileşene ayrılması, evsel atıksu arıtma tesislerinin modellenmesi konusunda önemli bir adım olmuştur [6,7]. Günümüzde ise evsel atıksu arıtma tesislerinin modellenmesi, birçok farklı amaç için kullanılmaktadır. Örneğin; Seggelke ve arkadaşları [8], evsel atıksu aritma tesisinin modellenmesi kapsamına aşırı yağış koşullarının etkisini incelemiştir. Dinamik modelleme çalışmalarında yaşam döngüsü değerlendirmesi entegrasyonu ile evsel atıksuların nütrient geri kazanım potansiyeli tahmin edilebilmektedir [9]. Evsel atıksu arıtma 
tesislerinde enerji verimliliğini sağlamak amacıyla tesis bazlı modelleme yaklaşımı ile aktif çamur prosesinin optimizasyonunun yapilması mümkündür [10].

Bu çalışmanın amacı, nütrient giderimi yapan tam ölçekli bir evsel atıksu arıtma tesisinin matematiksel olarak modellenmesidir. $\mathrm{Bu}$ kapsamda, modelleme bazlı yaklaşım ile incelenen atıksu arıtma tesisine ait atıksu ve deşarj karakterizasyonu istatiksel olarak incelenmiştir. Model kalibrasyonu ve doğrulaması çalışmaları gerçekleştirilmiş ve doğrulanan model parametreleri kullanılarak farklı senaryolar için atıksu arıtma tesisinin performansı ortaya konmuştur.

\section{MATERYAL VE METOT}

\section{1. İncelenen Atıksu Arıtma Tesisi}

İncelenen ileri biyolojik atıksu arıtma tesisi (İBAAT) üç kademeli olarak tasarlanmış olup, 2004 yılında devreye giren ilk kademesi 720.000 eşdeğer nüfus kapasitelidir [11]. Tesisin tasarımında kullanılan atıksu kirlilik yükleri ve tesise ait akım şeması sırasıyla Çizelge 1 ve Şekil 1'de verilmektedir. Tesis, biyolojik besi maddesi (azot ve fosfor) giderimi sağlayacak șekilde klasik $\mathrm{A}^{2} \mathrm{O}$ konfigürasyonuna sahiptir. Tesis mevcut durumda evsel atıksuları Su Kirliliği Kontrol Yönetmeliği Tablo 21.4'e uygun olacak şekilde arıtarak deşarj etmektedir [12].

Çizelge 1. İncelenen İBAAT tasarım debisi ve tasarıma özgü atıksu kirlilik yükleri

\begin{tabular}{|l|c|c|c|c|}
\hline Parametre & Birim & $\begin{array}{c}2010 \\
(1 . \text { Kademe })\end{array}$ & $\begin{array}{c}2020 \\
(2 . \text { Kademe })\end{array}$ & $\begin{array}{c}2030 \\
(3 . \text { Kademe })\end{array}$ \\
\hline Pik kuru hava debisi & $\mathrm{m}^{3} / \mathrm{gün}$ & 201,600 & 268,800 & 336,000 \\
\hline Pik yağışlı hava debisi & $\mathrm{m}^{3} / \mathrm{gün}$ & 432,000 & 576,000 & 720,000 \\
\hline Askıda katı madde (AKM) yükü & $\mathrm{kg} / \mathrm{gün}$ & 37,800 & 67,200 & 84,000 \\
\hline Kimyasal oksijen ihtiyacı (KOİ) yükü & $\mathrm{kg} / \mathrm{gün}$ & 64,800 & 115,200 & 114,000 \\
\hline Biyolojik oksijen ihtiyacı (BOİ 5 ) yükü & $\mathrm{kg} / \mathrm{gün}$ & 32,400 & 57,600 & 72,000 \\
\hline Toplam azot (TN) yükü & $\mathrm{kg} / \mathrm{gün}$ & 5,940 & 10,560 & 13,200 \\
\hline Toplam fosfor (TP) yükü & $\mathrm{kg} / \mathrm{gün}$ & 972 & 1,728 & 2,160 \\
\hline
\end{tabular}

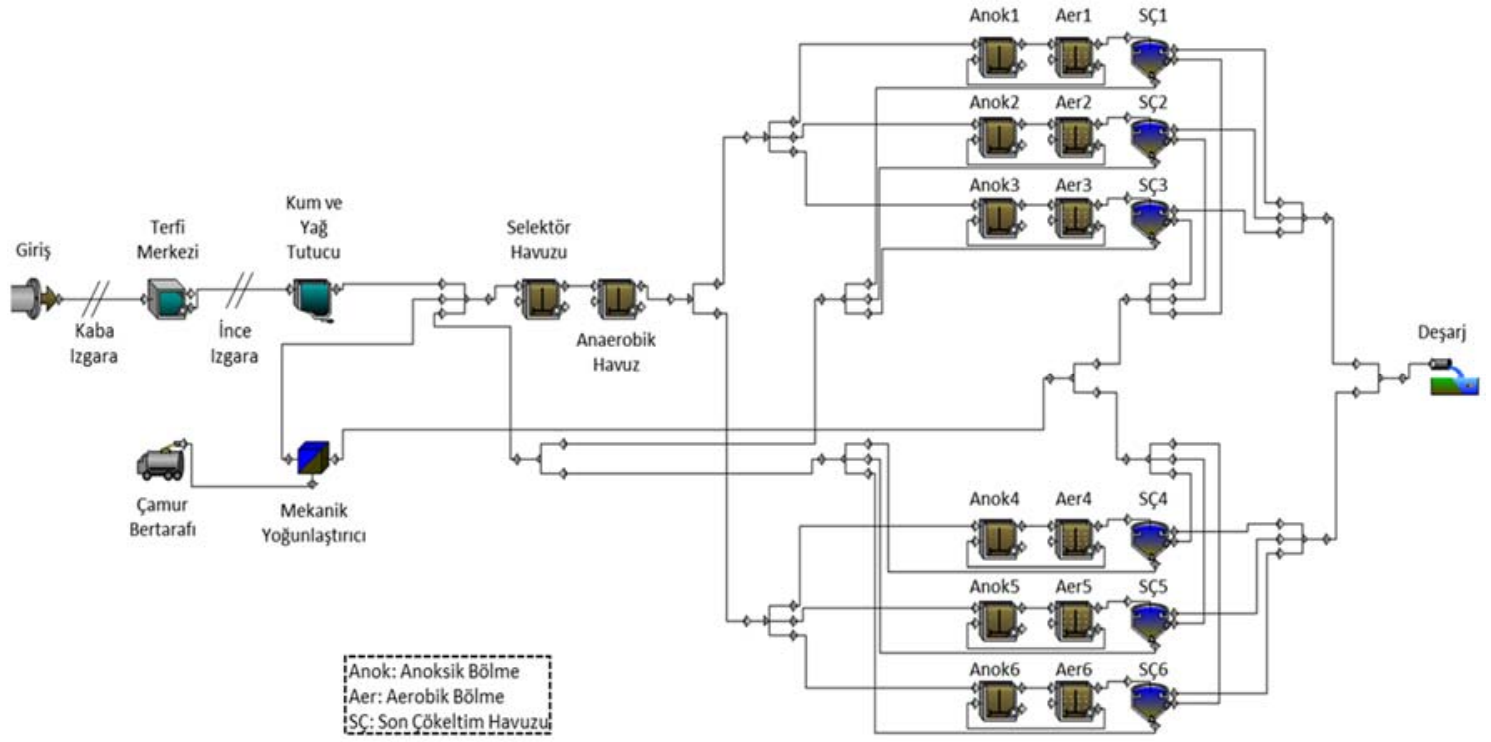

Şekil 1. İncelenen İBAAT’nin model bazlı proses akım şeması 
Tesiste atıksu, kaba ızgaraya iki ayrı kolektör ile ulaşmakta olup terfi merkezi ile ince 1zgaraya pompalanmaktadır. İnce 1zgaradan geçen atıksu kum ve yağ tutucuya iletilmekte ve akabinde $536 \mathrm{~m}^{3}$ hacimli selektör havuzuna ulaşmaktadır. Selektör havuzunda geri devir çamuru ile birleşen atıksu, fosfor salımının gerçekleştiği $18.610 \quad \mathrm{~m}^{3}$ hacmindeki anaerobik havuza geçmektedir. Ardından atıksu akımı paralel kollara ayrılmakta ve her biri $28.328 \mathrm{~m}^{3}$ hacminde 6 adet havalandirma havuzuna dağıtılmaktadır. Havalandırma havuzlarında aerobik bölgeden anoksik bölgeye içsel geri devir (IR) yapılmakta olup, IR oranı 4,4'tür. Anoksik bölgenin toplam havalandırma havuzu hacmine oranı $\left(\mathrm{V}_{\mathrm{d}} / \mathrm{V}\right)$ 0,2'dir. Akım havalandırma havuzlarının ardından her biri $2.380 \mathrm{~m}^{2}$ yüzey alanına sahip olan 6 adet son çökeltim tankına ulaşmakta ve burada çamur ile arıtılmış su birinden ayrılmaktadır. Arıtılmış su baraj gölüne deşarj edilmektedir. Son çökeltim tanklarında çöken aktif çamur, çamur geri devir havuzuna aktarılmakta ve buradan selektör havuzuna çamur geri devri yapılmaktadır. Fazla çamur ise mekanik belt susuzlaştırıcıda susuzlaştırıldıktan sonra bertaraf edilmektedir.

\subsection{Modelleme Çalışması}

Çalışmada Hydromantis Firması tarafından geliştirilen GPS-X Sürüm 6.5 simülasyon yazılımı kullanılmıştır [13]. GPS-X yazılımı biyolojik atıksu arıtma tesislerinin matematiksel modellenmesi amacıyla en sık olarak kullanılan ASM1, ASM2d, ASM3, Mantis2 ile Mantis3 modellerini ön tanımlı olarak içermektedir. Yazılımdaki çeşitli model kütüphaneleriyle oluşturulan proses akım şemaları üzerinden, tesislerin performansı kararlı durum ve dinamik koşullar için simüle edilebilmektedir.

İncelenen İBAAT, IWA Aktif Çamur Modeli No 2d (ASM2d) ile modellenmiştir [4]. ASM2d modeli atıksularda biyolojik azot fosfor giderimi sağlayan aktif çamur proseslerinin matematiksel olarak modellenmesi amacıyla geliştirilmiştir. Model 19 adet durum değişkeni ve 21 adet biyolojik/kimyasal proses içeren oldukça karmaşık bir yapıdadır [4]. ASM2d modeli büyük ölçekli evsel atıksu arıtma tesislerinin modellenmesinde yaygın bir şekilde kullanılmış olup, sistem performanslarının tahmininde başarılı sonuçlar elde edilmiştir [14-16].

\subsection{Veri Analizi}

Tesis işletmesi tarafından bir yıl boyunca izlenen giriş atıksu ve deşarj suyu karakterizasyonlarına ait parametreler öncelikle istatistiksel açıdan analiz edilmiş olup, veri setine aykırı olan değerler değerlendirme dişı tutulmuştur. İncelenen tesisin proses akım şeması GPS-X yazılımında oluşturulmuştur. İlk iki ayda sistemin işletiminde bazı değişiklikler yapıldığından, bu döneme ait veriler incelemeye dahil edilmemiş, çalışma 10 aylık veri (0-305 gün aralığı) üzerinden gerçekleştirilmiştir. Model parametre setindeki parametreler veri setinin ilk 180 günlük kısmı ile kalibre edilmiştir. Model doğrulama aşamasında ise kalibre edilen model 181-305 günleri arasındaki veri seti ile test edilmiş ve sonuçların uyumluluğu incelenmiştir.

Tesisin çamur yaşı ortalama 21 gün olarak tasarlanmıştır. Tesisin son çökeltim havuzları 0-147 gün aralığında 6 adet, 148-233 gün aralığında 5 adet, 234-263 gün aralığında 4 adet ve 264-305 gün aralığında 5 adet çalıştırılarak işletilmiştir. İşletmeye bağlı değişen son çökeltim tanklarının toplam yüzey alanı Çizelge 2'de verilmektedir.

Tesiste atıksu debisi her gün; KOİ, AKM, pH ve sicaklık parametreleri haftada 5 gün; $\mathrm{BOI}_{5}$ parametresi haftada 3 gün; TN, amonyum azotu $\left(\mathrm{NH}_{4}-\mathrm{N}\right)$, nitrit azotu $\left(\mathrm{NO}_{2}-\mathrm{N}\right)$ ve TP parametreleri ise haftada 1 gün ölçülmüştür. İncelenen İBAAT'ye ait giriş atıksuyunun ve çıkış suyunun karakterizasyonları sırasıyla Çizelge 3 ve Çizelge 4'te verilmiştir.

Çizelge 2. İşletmeye bağlı değişen son çökeltim tanklarının toplam yüzey alanı

\begin{tabular}{|c|c|}
\hline $\begin{array}{c}\text { Zaman } \\
\text { aralığı (gün) }\end{array}$ & $\begin{array}{c}\text { Son çökeltim tanklarının toplam } \\
\text { yüzey alanı }\left(\mathrm{m}^{2}\right)\end{array}$ \\
\hline $0-147$ & 14255 \\
\hline $148-233$ & 11879 \\
\hline $234-263$ & 9503 \\
\hline $264-305$ & 11879 \\
\hline
\end{tabular}


Tesisin atıksu karakterizasyon parametreleri ve dönemsel olarak değişen son çökeltim tank sayısı ile ilgili bilgiler dinamik girdi olarak modele tanımlanmıştır. Kullanılan model ile uyumlu giriş atıksu karakterizasyonu Çizelge 5'te verilmiştir.

Çizelge 3. 0-305 gün arasındaki işletme dönemi için giriş atıksu karakterizasyonu

\begin{tabular}{|c|c|c|c|c|c|c|c|}
\hline Parametre & Birim & Ortalama & Standart sapma & Medyan & Minimum & Maksimum & Veri adedi \\
\hline Debi & $\mathrm{m}^{3} /$ gün & 122.216 & \begin{tabular}{|l|}
22.789 \\
\end{tabular} & 122.000 & 60.000 & 165.000 & 194 \\
\hline KOİ & $\mathrm{mg} / \mathrm{L}$ & 384 & 111 & 370 & 177 & 935 & 186 \\
\hline BOİ & $\mathrm{mg} / \mathrm{L}$ & 164 & 45 & 161 & 45 & 258 & 84 \\
\hline BOİ/KOİ & - & 0,43 & 0,11 & 0,43 & 0,13 & 0,64 & 80 \\
\hline AKM & $\mathrm{mg} / \mathrm{L}$ & 197 & 68 & 188 & 93 & 572 & 186 \\
\hline $\begin{array}{l}\text { Uçucu Askıda Katı Madde } \\
\text { (UAKM) }\end{array}$ & $\mathrm{mg} / \mathrm{L}$ & 171 & 45 & 164 & 83 & 378 & 179 \\
\hline UAKM/AKM & - & 0,90 & 0,06 & 0,91 & 0,63 & 0,99 & 178 \\
\hline $\mathrm{TN}$ & $\mathrm{mg} / \mathrm{L}$ & 46,8 & 19,2 & 62,2 & 21,2 & 76,5 & 45 \\
\hline $\mathrm{NH}_{4}-\mathrm{N}$ & $\mathrm{mg} / \mathrm{L}$ & 28,9 & 9,3 & 33,0 & 12,6 & 44,7 & 35 \\
\hline $\mathrm{NH}_{4}-\mathrm{N} / \mathrm{TN}$ & - & 0,62 & 0,03 & 0,62 & 0,44 & 0,78 & 186 \\
\hline TP & $\mathrm{mg} / \mathrm{L}$ & 5,1 & 0,7 & 5,1 & 3,2 & 6,5 & 39 \\
\hline $\mathrm{pH}$ & - & 7,7 & 0,2 & 7,8 & 7,1 & 8,0 & 191 \\
\hline Sicaklık & ${ }^{\circ} \mathrm{C}$ & 19 & 5 & 18 & 9 & 27 & 195 \\
\hline
\end{tabular}

Çizelge 4. 0-305 gün arasındaki işletme dönemi için çıkış suyu karakterizasyonu

\begin{tabular}{|l|c|c|c|c|c|c|c|}
\hline Parametre & Birim & Ortalama & Standart sapma & Medyan & Minimum & Maksimum & Veri adedi \\
\hline KOI & $\mathrm{mg} / \mathrm{L}$ & 32 & 16 & 29 & 11 & 112 & 178 \\
\hline BOİ & $\mathrm{mg} / \mathrm{L}$ & 9 & 5 & 9 & 1 & 23 & 92 \\
\hline AKM & $\mathrm{mg} / \mathrm{L}$ & 14 & 14 & 9 & 2 & 84 & 177 \\
\hline $\mathrm{UAKM}$ & $\mathrm{mg} / \mathrm{L}$ & 10 & 11 & 6 & 1 & 63 & 177 \\
\hline $\mathrm{TN}$ & $\mathrm{mg} / \mathrm{L}$ & 7,9 & 2,0 & 7,5 & 4,8 & 13,1 & 38 \\
\hline $\mathrm{NH}_{4}-\mathrm{N}$ & $\mathrm{mg} / \mathrm{L}$ & 0,4 & 0,5 & 0,2 & 0,1 & 2,2 & 35 \\
\hline $\mathrm{NO}_{2}-\mathrm{N}$ & $\mathrm{mg} / \mathrm{L}$ & 0,2 & 0,3 & 0,1 & 0,0 & 1,2 & 35 \\
\hline Nitrat Azotu $\left(\mathrm{NO}_{3}-\mathrm{N}\right)$ & $\mathrm{mg} / \mathrm{L}$ & 6,3 & 1,5 & 6,1 & 4,0 & 10,2 & 32 \\
\hline TP & $\mathrm{mg} / \mathrm{L}$ & 2,5 & 0,8 & 2,4 & 1,2 & 4,7 & 59 \\
\hline
\end{tabular}

Çizelge 5. ASM2d modeli ile uyumlu giriş atıksu karakterizasyonu

\begin{tabular}{|c|c|c|}
\hline Gösterim & Açıklama & Oran $(\%)$ \\
\hline skoi/tkoi & Çözünmüş KOİ/KOİ & 37 \\
\hline xkoi/tkoi & Partiküler KOİ/KOİ & 63 \\
\hline si/tkoi & Çözünmüş inert KOİ/KOİ & 5 \\
\hline ss/tkoi & Biyolojik olarak ayrışabilen çözünmüş KOİ/KOİ & 32 \\
\hline $\mathrm{xi}$ /tkoi & Partiküler inert KOİ/KOİ & 16 \\
\hline $\mathrm{xs} / \mathrm{tkoi}$ & Biyolojik ayrışabilen partiküler KOİ/KOİ & 48 \\
\hline tboi/tkoi & $\mathrm{BOI}_{5} / \mathrm{KOI}$ & 52 \\
\hline uakm/akm & UAKM/AKM & 92 \\
\hline stkn/tkn & Çözünmüş toplam Kjeldahl azotu (TKN)/TKN & 63 \\
\hline $\mathrm{stp} / \mathrm{tp}$ & Çözünmüş fosfor/TP & 68 \\
\hline
\end{tabular}




\subsection{Senaryo Analizi}

Model kalibrasyon ve doğrulama çalışmalarını takiben işletme şartları ve atıksu karakterizasyonunun tesis performansı üzerindeki etkilerini incelemek amaciyla farklı senaryo çalışmaları yapılmıştır. İncelen senaryolar aşağıda açıklanmıştır:

- Senaryo 1: Atıksu azot yükü ile IR oranının deşarj TN konsantrasyonu üzerindeki etkilerinin karşılaştırılması:

Senaryo 1'de, tesise gelen atıksu azot yükünün $\% 20, \% 40$ ve $\% 60$ oranında artmasının ve pompaların IR oranı 1, 2, 3 ve 4,4 olacak şekilde çalıştırılmasının deşarj TN konsantrasyonu üzerindeki etkileri incelenmiştir. Bu çalışmadaki amaç, artan azot yükünü karşılayabilecek optimum IR oranının 16 farklı simülasyon sonucundan yararlanılarak tespit edilmesidir.

\section{- Senaryo 2: Atıksu azot yükü ile $V_{d} / V$ oranının deşarj TN konsantrasyonu üzerindeki etkilerinin karşılaştırılması:}

Senaryo 2'de, tesise gelen atıksu azot yükünün $\% 20, \% 40$ ve $\% 60$ oranında artmasının ve biyolojik havuzlardaki havalandırıcılar ayarlanarak aerobik ve anoksik bölge hacimlerinin değiştirilmesiyle elde edilen $\mathrm{Vd} / \mathrm{V}$ oranının $0,2,0,3,0,4$ ve 0,5 olarak değişmesinin deşarj TN konsantrasyonu üzerindeki etkileri incelenmiştir. Bu çalışmadaki amaç, artan azot yükünü karşılayabilecek optimum $\mathrm{Vd} / \mathrm{V}$ oranının 16 farklı simülasyon sonucundan yararlanılarak tespit edilmesidir.

\section{BULGULAR VE TARTIŞMA}

\subsection{Kalibrasyon Sonuçları}

ASM2d modeli oldukça karmaşık bir model olup, bir aktif çamur prosesinde gerçekleşen biyokimyasal reaksiyonlar birçok stokiyometrik ve kinetik parametre ile ifade edilmektedir. Model parametrelerinin kalibrasyonu iterasyon temelli bir işlemdir. Model sonuçları üzerinde en çok etkisi olan parametrelerin belirlenmesi ve özellikle bu parametrelerin kalibre edilmesi gerekmektedir. Örneğin; Boontian [17] ASM2d modeli ile gerçekleştirdiği duyarlılık analizi çalışmasında heterotrofik ve ototrofik mikroorganizmalar için en önemli parametrelerin çoğalma ve ölüm hızları olduğunu belirlemiştir. Uygun parametrelerin seçimi ile minimum sayıda parametre kullanılarak model sonuçlarının gerçek ölçümler ile uyumu arttırılabilir. Bu çalışmada da simülasyon sonuçları üzerinde en çok etki eden minimum sayıda kinetik parametre, havalandırma havuzundaki UAKM ve AKM konsantrasyonu model çıktılarını gerçek verilerle örtüştürmek üzere kalibre edilmiştir (Çizelge 6). Kinetik parametreler dişında çamur çökelme özellikleri (Çamur hacim indeksi (SVI) ve çökelme verimi parametresi) dinamik olarak kalibre edilmiştir. Havalandırma havuzundaki UAKM ve AKM konsantrasyonlarına ait model verileri gerçek verilerle örtüştürüldükten sonra tesisin çık1ş suyunda ölçülen KOİ, TN ve $\mathrm{NH}_{4}-\mathrm{N}$ parametreleri ile uyumu Şekil 2'de verilmektedir. Kalibrasyon sonrasında tesisin çamur yaşı hesaplanmış ve 39-94 gün aralığında (ortalama 60 gün) değiştiği görülmüştür. Tesisin, tasarım çamur yaşından (21 gün) oldukça yüksek bir aralıkta işletildiği sonucuna varılmıştır.

Çizelge 6. Kalibre edilen kinetik katsayılar

\begin{tabular}{|l|c|c|c|}
\hline Kinetik Katsayı & Birim & $\begin{array}{c}\text { Ön Tanımlı } \\
\text { Değer }\end{array}$ & $\begin{array}{c}\text { Kalibrasyon sonucu elde } \\
\text { edilen değer }\end{array}$ \\
\hline Ototrofik bakteri çoğalma hızı & $1 /$ gün & 1,0 & 1,5 \\
\hline Ototrofik bakteri ölüm hızı & $1 /$ gün & 0,15 & 0,1 \\
\hline $\begin{array}{l}\text { Heterotrof bakterinin anoksik şartlarda çoğalma } \\
\text { hızını yavaşlatma faktörü }\end{array}$ & - & 0,8 & 0,6 \\
\hline Nitrat için yarı doygunluk katsayısı & $\mathrm{mg} \mathrm{N} / \mathrm{L}$ & 0,5 & 0,9 \\
\hline
\end{tabular}




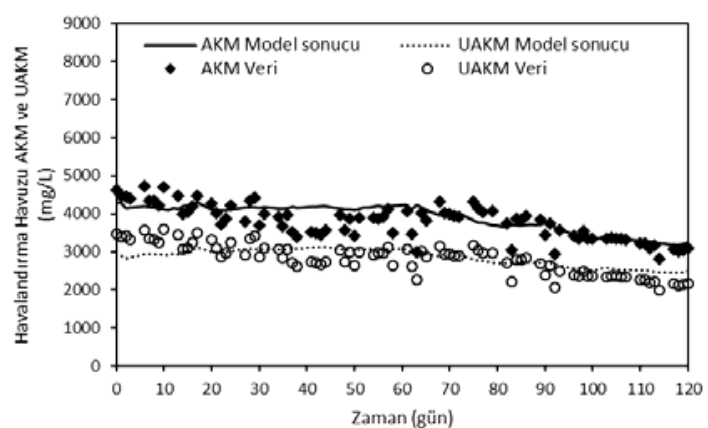

(a)

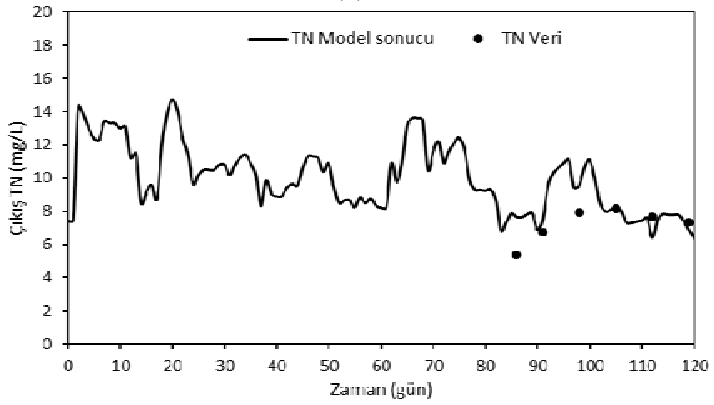

(c)

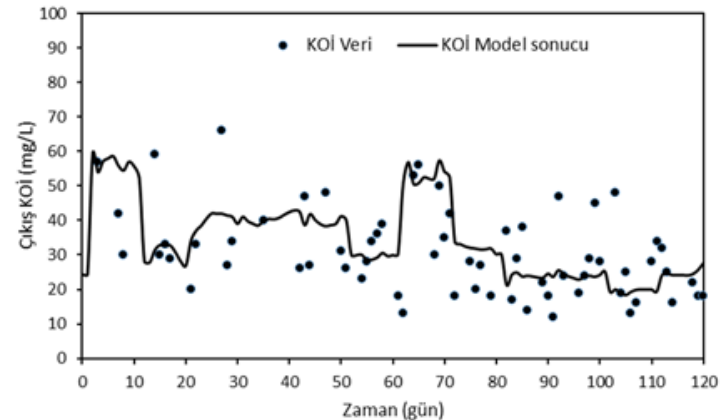

(b)

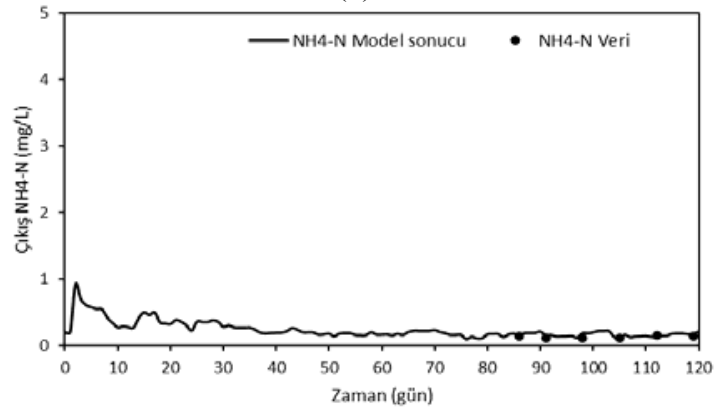

(d)

Şekil 2. Kalibrasyon aşamasında elde edilen simülasyon sonuçları ve tesis çıkış suyundaki (a) AKM ve UAKM, (b) KOİ, (c) TN ve (d) $\mathrm{NH}_{4}-\mathrm{N}$ konsantrasyonları

\subsection{Modelin Doğrulanması}

Model doğrulama aşamasında kalibre edilen parametreler, 121-305 günleri aralı̆̆ında tesisten elde edilen veriler için test edilmiştir. Havalandırma havuzundaki UAKM ve AKM ile tesis çıkış suyunda ölçülen KOİ, TN ve $\mathrm{NH}_{4}-\mathrm{N}$ konsantrasyonları ile doğrulama aşamasında elde edilen simülasyon sonuçları Şekil 3'te verilmektedir. Kalibre edilen modelin performansını belirlemek üzere; havalandırma havuzu UAKM ve AKM konsantrasyonları için simülasyon (model) sonuçları ile ölçüm sonuçlarının uyumu; mutlak rölatif hatalar ortalaması kullanılarak değerlendirilmiştir. Model sonuçları ile ölçülmüş verilerin arasındaki mutlak rölatif hataların ortalaması $\% 10$ 'dan daha düşük ise, model yüksek doğrulukta; \%10- \%30 aralığında ise, orta doğrulukta; \%30'dan fazla ise model sonuçlarının sistemin genel niteliğini ortaya koyduğu taktirde kalitatif olduğu kabul edilmiştir [18]. Havalandırma havuzundaki UAKM ve AKM konsantrasyonları için model ve ölçüm sonuçları arasındaki mutlak rölatif hatalar ortalaması kalibrasyon adımında \%10, doğrulama adımında ise $\% 12$ 'dir. $\mathrm{Bu}$ sonuçlara göre, söz konusu parametreler için modelin kalibrasyon adımında yüksek doğrulukta ve doğrulama adımında ise orta doğrulukta olduğu tespit edilmiştir. Çıkış suyu KOİ konsantrasyonu için ise mutlak rölatif hatalar ortalaması kalibrasyon adımı için \%35, doğrulama aşaması için \%50'dir. Çıkış suyundaki KOİ konsantrasyonu ölçüm verilerin oldukça dağınık olmasına rağmen, model sonuçlarının veri eğilimine uyumlu olduğu ve sistemin genel davranışını temsil ettiği düşünülmektedir. Çıkış suyunda TN parametresi için ise kalibrasyon ve doğrulama adımında mutlak rölatif hatalar ortalaması veri azlığı nedeniyle anlamlı sonuç vermemektedir. Ancak doğrulama adımında model sonuçlarının veri eğilimine uyumlu olduğu görülmektedir. Tesiste özellikle yılın sonuna doğru sıcaklıkların düşmesi ile birlikte çıkış suyunda $\mathrm{NH}_{4}-\mathrm{N}$ ve $\mathrm{TN}$ konsantrasyonlarında artışlar gözlenmiştir. Model bu dinamik değişimleri başarılı bir şekilde simüle edebilmiştir. 


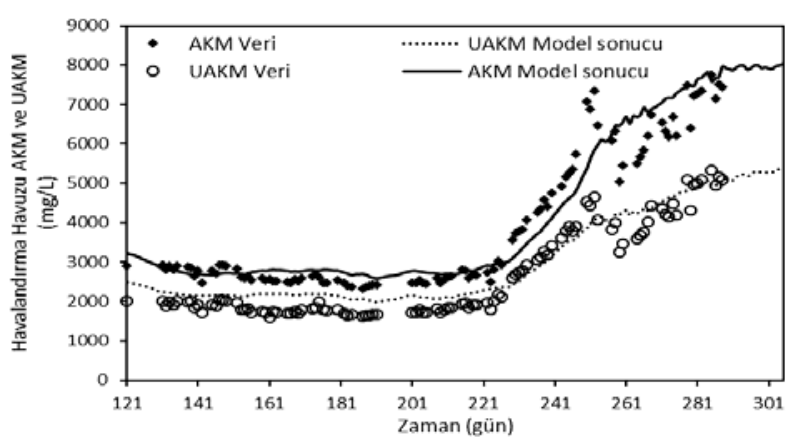

(a)

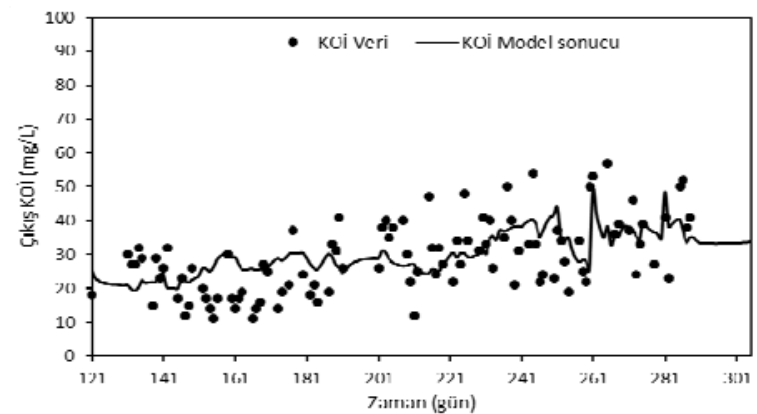

(b)

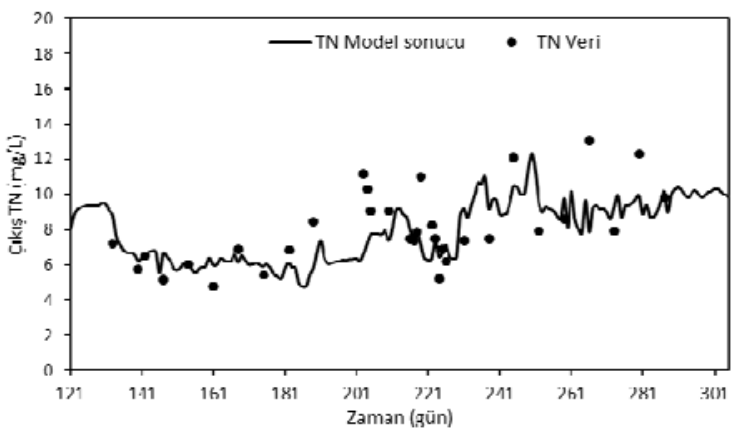

(c)

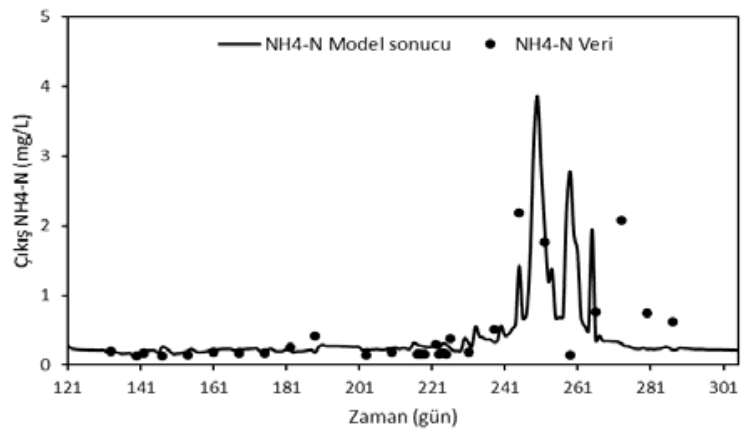

(d)

Şekil 3. Modelin doğrulanması aşamasında elde edilen simülasyon sonuçları ve tesis çıkış suyundaki (a) AKM ve UAKM, (b) KOİ, (c) TN ve (d) $\mathrm{NH}_{4}-\mathrm{N}$ konsantrasyonlar1 


\subsection{Senaryo Analizi}

Doğrulanan model ile tesis işletme şartları ve atıksu karakterizasyonunun çıkış suyu TN konsantrasyonuna etkisi farklı senaryolar için incelenmiştir. Tesis mevcut durumda SKKY Tablo 24.1'e tabi olup, TN ve TP parametreleri için bir deşarj sınırlaması bulunmamaktadır. Ancak, tesis bu parametreleri de yüksek giderme verimleri ile arıtabilmektedir. Gelecekte, özellikle Kentsel
Atıksu Arıtımı Yönetmeliği (KAAY)'ne tabi olunması durumunda azot parametresi için bir sinırlama getirilebilecektir [19]. Dolayısıyla, tesisin optimum işletme şartlarının belirlenmesi gerekmektedir. Senaryo 1'de atıksu azot yükü ve IR'nin, deşarj TN konsantrasyonu üzerindeki etkileri, Senaryo 2'de ise atıksu azot yükü ve $\mathrm{V}_{\mathrm{d}} / \mathrm{V}$ oranının deşarj TN konsantrasyonu üzerindeki etkileri incelenmiş ve sonuçlar Şekil 4'te verilmiştir.

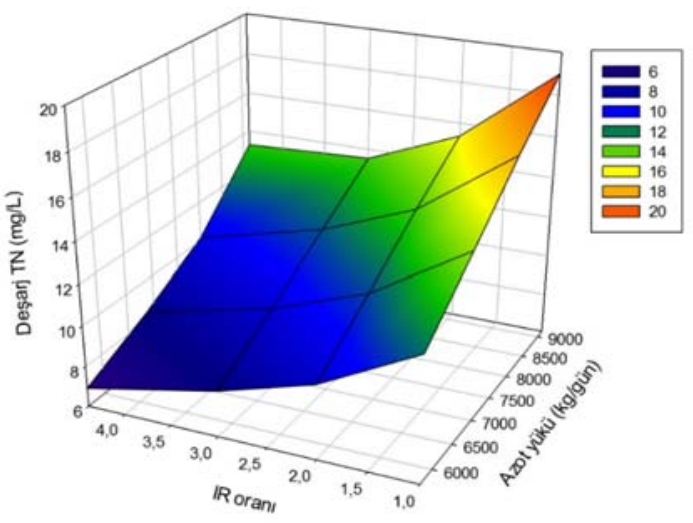

(a)

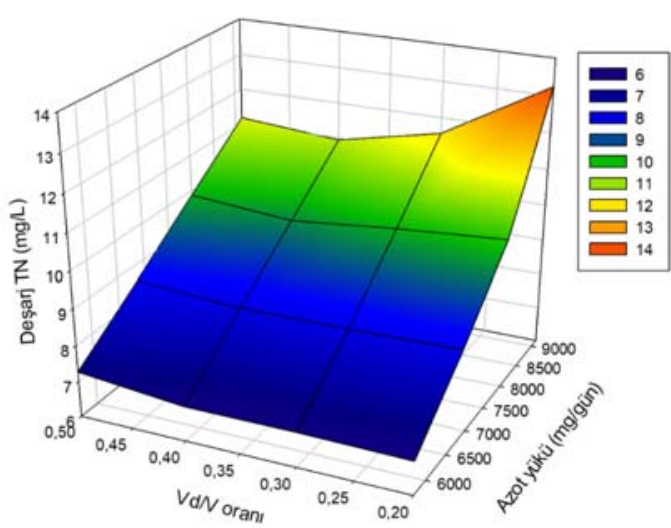

(b)

Şekil 4. Çalışmada incelenen senaryolar: (a) Senaryo 1: Deşarj TN konsantrasyonuna etkileri bakımından atıksu azot yükü ve IR oranının karşılaştırılması, (b) Senaryo 2: Deşarj TN konsantrasyonuna etkileri bakımından atıksu azot yükü ve $\mathrm{V}_{\mathrm{d}} / \mathrm{V}$ oranı karşılaştırılması

Şekil 4 (a)'da artan atıksu azot yükü ile deşarj TN konsantrasyonunun arttığı görülmektedir. Atıksu azot yükünün $6.000 \mathrm{~kg} /$ gün olduğu mevcut durum için farklı IR oranlarının deşarj TN konsantrasyonu üzerindeki etkisi incelendiğinde; en düşük deşarj TN konsantrasyonunun $(6,9 \mathrm{mg}$ N/L) IR oranı 4,4 iken gerçekleştiği, ancak IR oranı 2,5 olduğunda dahi KAAY'de 100.000 eşdeğer nüfusun üzerindeki tesisler için belirtilen $10 \mathrm{mg} / \mathrm{L}$ TN deşarj standardının sağlanabildiği (deşarj TN konsantrasyonu $8,8 \mathrm{mg} \mathrm{N} / \mathrm{L}$ ) görülmektedir. IR oranı 2,5 olduğunda, atıksu azot yükü $6.500 \mathrm{~kg} /$ gün'e kadar artış gösterse de tesisin TN standardını sağlayabileceği tahmin edilmektedir. Senaryo 1 incelendiğinde, tesis IR oran 4,4 yerine 2,5 olacak şekilde çalıştırıldığında, deşarj standardı sağlanarak içsel geri devir pompalarının daha az çalıştırılmasına bağlı olarak enerji tasarrufu sağlanabileceği sonucuna varılmaktadır. Ayrıca, tesiste otomasyon sistemi kullanılarak özellikle debi ve yükün azaldığı gece saatlerinde içsel geri devir debisinin azaltılması suretiyle enerji tasarrufu sağlanabileceği öngörülmektedir.

Senaryo 2'de, atıksu azot yükü ile $\mathrm{V}_{\mathrm{d}} / \mathrm{V}$ oranının, deşarj TN konsantrasyonu üzerindeki etkisi karşılaştırılmıştır (Şekil 4 (b)). Artan atıksu azot yükü ile deşarj TN konsantrasyonunun artacağı ancak artan $\mathrm{V}_{\mathrm{d}} / \mathrm{V}$ oranı ile $\mathrm{TN}$ standardının sağlanabileceği görülmektedir. Atıksu azot yükünün $6.000 \mathrm{~kg} /$ gün olduğu mevcut durum için farkl $\mathrm{V}_{\mathrm{d}} / \mathrm{V}$ oranlarının deşarj $\mathrm{TN}$ konsantrasyonu üzerindeki etkileri incelendiğinde; en düşük deşarj TN konsantrasyonunun $(6,9 \mathrm{mg} \mathrm{N} / \mathrm{L}) \mathrm{V}_{\mathrm{d}} / \mathrm{V}$ oran 1 0,2 olduğunda gerçekleştiği, ancak $\mathrm{V}_{\mathrm{d}} / \mathrm{V}$ oranı 0,5 olduğunda da deşarj standardının sağlanacağı 
(deşarj TN konsantrasyonu 7,3 $\mathrm{mg} \quad \mathrm{N} / \mathrm{L}$ ) görülmektedir. $\mathrm{V}_{\mathrm{d}} / \mathrm{V}$ oranı 0,5 olduğunda, atıksu azot yükü $8.000 \mathrm{~kg} /$ gün'e kadar artış gösterse de tesisin TN standardını sağlayabileceği tahmin edilmektedir. Daha yüksek azot yüklerinde azalan nitrifikasyon hacmine bağlı olarak TN konsantrasyonun standardın bir miktar üzerinde kalabileceği tahmin edilmektedir. Ancak atıksu azot yükünün $9.000 \mathrm{~kg} /$ gün civarlarında olduğu durumlarda sistem $0,4 \quad \mathrm{~V}_{\mathrm{d}} / \mathrm{V}$ oranı ile KAAY limitlerini sağlayabilecektir. Senaryo 2 incelendiğinde, tesiste $\mathrm{V}_{\mathrm{d}} / \mathrm{V}$ oranı 0,2 yerine 0,5 olduğunda, havalandırma enerjisi ihtiyacının azalacağı ve ileride sıkılaşabilecek deşarj standartlarının da sağlanabileceği sonucuna varılmaktadır.

\section{SONUÇLAR}

Yapılan çalışmada, biyolojik nütrient giderimi sağlayan 720.000 eşdeğer nüfus kapasiteli bir atıksu arıtma tesisi ASM2d modeli kullanılarak kalibre edilmiş ve matematiksel olarak modellenmiștir. Tesis mevcut durumda tabi olduğu SKKY Tablo 24.1'e göre çıkış suyu kalitesi açısından azot standardına bağlı değildir. Ancak gelecekte KAAY'ye göre $10 \mathrm{mg} / \mathrm{L}$ TN deşarj konsantrasyonu limitine tabi olma durumu söz konusudur. $\mathrm{Bu}$ nedenle tesiste giriş azot yükü, IR ve $V_{d} / V$ oranlarının, çıkış suyundaki TN konsantrasyonu üzerindeki etkilerini belirlemek üzere iki farklı senaryo oluşturulmuş ve tesisin deşarj standardını sağlarken aynı zamanda minimum enerji tüketimini sağlayan en uygun işletme koşulları belirlenmiştir. Senaryo 1'de, giriş azot yükü ve IR oranının çıkıș TN konsantrasyonu üzerindeki etkileri karşılaştırılmıştır. Buna göre, mevcut durumdaki azot yükünü gidermek üzere 4,4 IR oranı ile çalıştırılan tesisin, 2,5 IR oranı ile çalıştırıldığında da deşarj hattında $10 \mathrm{mg} / \mathrm{L}$ 'nin altında TN konsantrasyonu sağlayabileceği tespit edilmiştir. $\mathrm{Bu}$ durumda tesiste mevcut durumda daha düşük bir geri devir oranı ile enerji tasarrufu elde edilirken, tesis çıkışında istenen deşarj TN konsantrasyonu da sağlanabilmektedir. Senaryo 2'de ise atıksu azot yükü ile $\mathrm{V}_{\mathrm{d}} / \mathrm{V}$ oranının çıkış $\mathrm{TN}$ konsantrasyonu üzerindeki etkisi karşılaştırılmıştır. Senaryo 2 kapsamında, $\mathrm{V}_{\mathrm{d}} / \mathrm{V}$ oranının 0,2 yerine 0,5 olarak ayarlanarak tesisin işletilmesi halinde, çıkışta
$10 \mathrm{mg} / \mathrm{L}$ TN konsantrasyonunun sağlanabileceği sonucuna ulaşılmıştır. İncelenen tesis daha yüksek $\mathrm{V}_{\mathrm{d}} / \mathrm{V}$ oranı ile işletildiğinde, biyolojik havuzlardaki havalandırma ihtiyacı azalarak enerji tasarrufu elde edilmekte ve deşarj standartları da sağlanabilmektedir.

\section{KAYNAKLAR}

1. Kumar, M., Singh, R., 2017. Performance Evaluation of Semi Continuous Vertical Flow Constructed Wetlands (SC-VF-CWs) for Municipal Wastewater Treatment. Bioresource Technology, 232, 321-330.

2. Ozgun, H., 2015. Anaerobic Membrane Bioreactors for Cost-Effective Municipal Water Reuse. Doktora Tezi, İstanbul Teknik Üniversitesi-Delft University of Technology, Türkiye-Hollanda.

3. Li, W.W., Yu, H.Q., Rittmann, B.E., 2015. Chemistry: Reuse water pollutants. Nature, 528, 29-31.

4. Henze, M., Gujer, W., Mino, T., van Loosdrecht, M.C.M. ,2000. Activated Sludge Models ASM1, ASM2, ASM2d and ASM3. IWA Scientific and Technical Report No. 9. IWA Publishing. London, UK.

5. Gujer, W., 2006. Activated Sludge Modelling: Past, Present and Future. Water Science and Technology, 53(3), 111-119.

6. Dold, P.L., Ekama, G.A., Marais, G.V.R., 1980. A General Model for the Activated Sludge Process. Prog. Wat. Tech., 12(6), 47-77.

7. Marais, G.V.R., Ekama, G.A., 1976. The Activated Sludge Process. Part 1 - Steady State Behaviour. Water SA, 2(4), 163.

8. Seggelke, K., Rosenwinkel, K.H., Vanrolleghem, P., Krebs, P., 2004. Integrated Operation of Sewer System and WWTP by Simulation-based Control of the WWTP Inflow. In Proceedings of 6 . International Conference on Urban Drainage Modelling, Dresden, 15-17 September 2004, 307-315.

9. Bisinella de Faria, A.B., Sperandio, M., Ahmadi, A., Tiruta-Barna, L., 2015. Evaluation of New Alternatives in Wastewater Treatment Plants Based on Dynamic Modelling and Life Cycle Assessment (DM-LCA). Water Research, 84, 99-111. 
10. Descoins, N., Deleris, S., Lestienne, R., Trouve, E., Marechal, F., 2012. Energy Efficiency in Waste Water Treatments Plants: Optimization of Activated Sludge Process Coupled with Anaerobic Digestion. Energy, 41(1), 153-164.

11. Özdemir, Ö., 2016. İleri Biyolojik Atıksu Arıtma Tesisinde Sürdürülebilir İşletme İçin Revizyon ve Enerji Verimliliği: Malatya Örneği. Adıyaman Üniversitesi Mühendislik Bilimleri Dergisi 5, 9-20.

12. ÇŞB, 2004. T.C. Çevre ve Şehircilik Bakanlığı, $\mathrm{Su}$ Kirliliği Kontrolü Yönetmeliği. Resmi Gazete Sayıs1: 25687.

13. Hydromantis, 2017. Hydromantis Web Sitesi http://www.hydromantis.com/GPS-X.html

14. Hvala, N., Vrečko, D., Levstek, M., Bordon, C., 2017. The Use of Dynamic Mathematical Models for Improving the Designs of Upgraded Wastewater Treatment Plants. Journal of Sustainable Development of Energy, Water and Environment Systems 5(1), 15-31.

15. Machado, V.C., Lafuente, J., Baeza, J.A., 2014. Activated Sludge Model 2d Calibration with Full-scale WWTP Data: Comparing Model Parameter Identifiability with Influent and Operational Uncertainty. Bioprocess and Biosystems Engineering 37, 1271-1287.

16. Ferrer, J., Morenilla, J.J., Bouzas, A., GarciaUsach, F., 2004. Calibration and Simulation of Two Large Wastewater Treatment Plants Operated for Nutrient Removal. Water Science and Technology 50(6), 87-94.

17. Boontian, N.A., 2012. Calibration Approach Towards Reducing ASM2d Parameter Subsets in Phosphorus Removal Processes. World Academy of Science, Engineering and Technology 6, 805-811.

18. Batstone, D.J., Keller, J., 2003. Industrial Applications of the IWA Anaerobic Digestion Model No. 1 (ADM1). Water Science and Technology, 47(12), 199-206.

19. ÇŞB, 2006. T.C. Çevre ve Şehircilik Bakanlı̆̆ı, Kentsel Atıksu Arıtımı Yönetmeliği. Resmi Gazete Sayıs1: 26047. 
